Nervenarzt 2018 $89: 1388-1399$ https://doi.org/10.1007/s00115-018-0607-0 Online publiziert: 27 . September 2018 (C) Der/die Autor(en) 2018 CrossMark

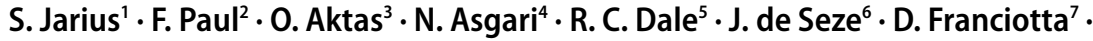
K. Fujihara ${ }^{8} \cdot$ A. Jacob ${ }^{9} \cdot$ H. J. Kim ${ }^{10} \cdot$ I. Kleiter ${ }^{11} \cdot$ T. Kümpfel ${ }^{12} \cdot$ M. Levy ${ }^{13} \cdot$ J. Palace $^{14}$. K. Ruprecht ${ }^{15} \cdot$ A. Saiz ${ }^{16} \cdot$ C. Trebst $^{17} \cdot$ B. G. Weinshenker ${ }^{18} \cdot$ B. Wildemann ${ }^{19}$

${ }^{1}$ AG Molekulare Neuroimmunologie, Neurologische Klinik, Universitätsklinikum Heidelberg, OttoMeyerhof-Zentrum, Heidelberg, Deutschland; ${ }^{2}$ Experimental and Clinical Research Center, NeuroCure Clincial Research Center, und Berliner Institut für Gesundheitsforschung, Max-Delbrück-Zentrum für Molekulare Medizin und Charité - Universitätsmedizin Berlin, Gliedkörperschaft der Freien Universität Berlin und der Humboldt-Universität zu Berlin, Berlin, Deutschland; ${ }^{3}$ Neurologische Klinik, HeinrichHeine-Universität Düsseldorf, Düsseldorf, Deutschland; ${ }^{4}$ Department of Neurology, University of Southern Denmark, Odense, Dänemark; ${ }^{5}$ Children's Hospital at Westmead, University of Sydney, Sydney, Australien; ${ }^{6}$ Department of Neurology, Hôpital de Hautepierre, Strasbourg Cedex, Frankreich; ${ }^{7}$ Neuroimmunology Laboratory, IRCCS Mondino Foundation, Pavia, Italien; ${ }^{8}$ Department of Multiple Sclerosis Therapeutics, Tohoku University Graduate School of Medicine, Sendai, Japan; ${ }^{9}$ The Walton Centre, Walton Centre NHS Foundation Trust, Liverpool, Großbritannien; ${ }^{10}$ Department of Neurology, Research Institute and Hospital of National Cancer Center, Goyang, Südkorea; "Marianne-Strauß-Klinik, Behandlungszentrum Kempfenhausen für Multiple Sklerose Kranke gGmbH, Berg, Deutschland; ${ }^{12}$ Institut für Klinische Neuroimmunologie, Ludwig-Maximilians-Universität, München, Deutschland; ${ }^{13}$ Department of Neurology, Johns Hopkins Hospital, Cleveland, USA; ${ }^{14}$ Nuffield Department of Clinical Neurosciences, John Radcliffe Hospital, Oxford, Großbritannien; ${ }^{15} \mathrm{Klinik}$ für Neurologie mit experimenteller Neurologie, Charité - Universitätsmedizin Berlin, Gliedkörperschaft der Freien Universität Berlin und der HumboldtUniversität zu Berlin, Berlin, Deutschland; ${ }^{16}$ Service of Neurology, Hospital Clinic, and Institut d'Investigacions Biomèdiques August Pi i Sunyer (IDIBAPS), Universitat de Barcelona, Barcelona, Spanien; ${ }^{17}$ Neurologische Klinik, Medizinische Hochschule Hannover, Hannover, Deutschland; ${ }^{18}$ Department of Neurology, Mayo Clinic, Rochester, USA; ${ }^{19}$ AG Molekulare Neuroimmunologie, Neurologische Klinik, Universitätsklinikum Heidelberg, Heidelberg, Deutschland

\title{
MOG-Enzephalomyelitis: Internationale Empfehlungen zu Diagnose und Antikörpertestung
}

ten, wurde ursprünglich angenommen, dass Antikörper gegen MOG an der Pathogenese der multiplen Sklerose (MS) beteiligt sind. Neuere Untersuchungen unter Verwendung von zellbasierten Assays der neuen Generation zeigen hingegen übereinstimmend eine robuste Assoziation von IgG-Antikörpern gegen vollständiges, konformationell intaktes humanes MOG-Protein (MOG-IgG) mit (meist rezidivierender) Optikusneuritis (ON), Myelitis und Hirnstammenzephalitis sowie mit ADEM(akute disseminierte Enzephalomyelitis)-artigen Präsentationen statt mit klassischer MS [20, 23, 24, 33, 34, 36, 47, 51, 57-59].

Basierend auf (a) immunologischen Studien, die eine direkte pathogene Wirkung von MOG-IgG nahelegen, (b) neuropathologischen Studien, die in Läsionen von MOG-IgG-positiven Patienten histopathologische Merkmale eines autoantikörper- und komplement- vermittelten Pathomechanismus fanden, die bei der Mehrzahl der Patienten mit klassischer MS nicht nachweisbar sind, (c) serologischen Studien, die zeigen konnten, dass Aquaporin-4(AQP4)-IgG so gut wie nie gleichzeitig mit MOG-IgG vorliegt, und (d) Kohortenstudien, die deutliche Unterschiede in der klinischen und paraklinischen Präsentation, dem Ansprechen auf die immuntherapeutische Behandlung und der klinischen Prognose nahelegen, gilt MOG-IgG inzwischen als pathognomonischer Marker einer eigenständigen Erkrankung, die sich sowohl von der klassischen MS als auch von der AQP4-IgG-positiven Neuromyelitis-optica-SpektrumErkrankung (engl. „neuromyelitis optica spectrum disorder" [NMOSD]) unterscheidet und als MOG-IgG-assoziierte Enzephalomyelitis oder kurz als MOGEnzephalomyelitis (MOG-EM) bezeichnet wird $[15,57,70]$. 
MOG-EM und klassische MS zeigen jedoch phänotypisch, d.h. klinisch und radiologisch, relevante Überschneidungen [23, 60]: In der Mehrzahl der Fälle nimmt die MOG-EM, wie die MS, einen schubförmigen Verlauf [23, 59], zumindest bei Erwachsenen, und 33\% bzw. $15 \%$ der erwachsenen Patienten mit MOG-EM erfüllen wenigstens einmal im Krankheitsverlauf die McDonald- bzw. die Barkhof-Kriterien für MS [23, 60]. Dementsprechend wurde bei vielen $\mathrm{Pa}$ tienten mit MOG-EM in der Vergangenheit fälschlich eine MS diagnostiziert [20, 23]. Eine solche Fehlklassifizierung hat jedoch potenziell relevante therapeutische Implikationen: (a) Präliminäre Daten legen nahe, dass einige Medikamente, die für die Behandlung der MS zugelassen sind, aufgrund von Unterschieden in der Immunpathogenese in der Behandlung der MOG-EM, ähnlich wie bei AQP4IgG-positiver NMOSD, unwirksam oder sogar schädlich sein könnten [20, 23, 43, 64, 67]; (b) die MOG-EM ist vermutlich mit einem höheren Risiko für erneute Schubaktivität nach Beendigung der Akutbehandlung mit Steroiden verbunden und erfordert daher eine sorgfältige Überwachung und vermutlich ein vorsichtiges Ausschleichen der Akuttherapie $[6,23,38$, 40, 45, 53]; und (c) MOGIgG-positive Patienten scheinen im akuten Schub besonders gut auf antikörperdepletierende Behandlungen wie Plasmaaustausch (PEX) oder Immunadsorption (IA) anzusprechen [20, 23, 34, 46, 60 , 61] sowie im Langzeitverlauf auf B-Zellgerichtete Therapien (z.B. Rituximab), auf intravenöse Immunglobuline (IVIG; vor allem bei Kindern [13]) sowie auf Immunsuppressiva [13, 23, 44, 59, 60]. Daher wird derzeit eine zunehmende Anzahl von Patienten mit vermuteter oder anhand der derzeit gültigen diagnostischen Kriterien formal etablierter MS auf MOG-IgG untersucht.

Das Screening von großen, nichtselektierten Populationen auf seltene Biomarkerverringert jedoch generell den prädiktiven Wert von diagnostischen Tests [27, 32]. Selbst wenn Assays mit hoher Spezifität ( $\geq 99 \%$ ) verwendet werden, kann die Zahl der falsch positiven (FP) Ergebnisse leicht die Zahl der richtig positiven (RP) Ergebnisse übersteigen, wenn die Präva- lenz des untersuchten Markers niedrig und die Anzahl der getesteten Proben hoch ist. Dies gilt auch für die MOGIgG-Serologie. Basierend auf einer hypothetischen Prävalenz von $1 \%$ genuinen MOG-IgG-positiven Fällen unter allen Patienten, die derzeit die formalen Diagnosekriterien der MS erfüllen, würde eine Testung von 100.000 Patienten mittels eines nahezu fehlerfreien, $99 \%$ spezifischen und $100 \%$ empfindlichen Tests zu einem nicht akzeptablen Verhältnis von 990 FP-Ergebnissen zu 1000 RP-Ergebnissen führen. Daher sollte ein nichtselektives Screening aller Patienten mit vermuteter oder formal etablierter MSDiagnose auf MOG-IgG vermieden werden und sind spezifischere Kriterien für die MOG-IgG-Untersuchung dringend erforderlich.

In dieser Arbeit schlagen wir erstmalig auf Expertenkonsens beruhende Indikationen für die MOG-IgG-Testung vor. Zusätzlich geben wir dem Leser eine Liste von begleitenden Befunden an die Hand, die als untypisch für die MOG-EM gelten können („red flags“) und Anlass geben sollten, die Validität eines positiven MOG-IgG-Testergebnisses kritisch $\mathrm{zu}$ hinterfragen. Abschließend geben wir Empfehlungen zur Testmethodik, zur Probenentnahme und zur Dateninterpretation und präsentieren erstmalig Diagnosekriterien für die MOG-EM.

\section{Methoden}

PubMed-Suche nach Artikeln, die zwischen Februar 2007 und Februar 2017 veröffentlicht wurden und folgende Begriffe in Titel oder Abstract enthielten: („myelin oligodendrocyte glycoprotein“" OR MOG) AND (antibody OR antibodies OR „immunoglobulin G“ OR IgG). Alle auf diese Weise identifizierten Artikel wurden von einer Kerngruppe von Ärzten (SJ, BW, FP, KR) hinsichtlich klinischer und paraklinischer Befunde analysiert, die häufig in Verbindung mit MOG-IgG-assoziierter ZNS-Demyelinisierung berichtet wurden und die daher eine MOG-IgG-Testung rechtfertigen, wie auch hinsichtlich möglicher „red flags“, d.h. Befunden, die, wenn vorliegend, eher gegen das Vorliegen einer MOG-EM sprechen. Basierend auf dem
Konsens der Kerngruppe wurde eine erste Fassung formuliert und anschließend an eine breitere Gruppe von Experten aus Australien, Dänemark, Frankreich, Deutschland, Italien, Japan, Südkorea, Spanien, Großbritannien und den USA zur Diskussion und Optimierung weitergeleitet. Die Mitglieder des Gremiums wurden von der Kerngruppe basierend aufEminenz und früheren Beiträgen zum Thema eingeladen. Basierend auf einer Peer-to-Peer-Diskussion der einzelnen Empfehlungen mit den Mitgliedern des Panels wurde ein finales Set evidenzwie eminenzbasierter Empfehlungen erstellt, denen alle Mitglieder zustimmten. Die hier gegebenen Empfehlungen sind als Expertenkonsens zu verstehen (Evidenzklasse IV).

\section{Empfehlungen zur MOG-IgG- Testung}

In $\bullet$ Tab. 1 schlagen wir Indikationen für die Testung auf MOG-IgG vor. Diese basieren auf klinischen und paraklinischen Befunden, die typisch für MOGEM und/oder atypisch für MS sind und die nach Ansicht der Panel-Mitglieder mit Prä-Test-Odds assoziiert sind, die ausreichen, um eine Testung auf MOGIgG zu rechtfertigen, oder die aufgrund potenziell signifikanter therapeutischer Konsequenzen eines positiven Testergebnisses nach Expertenkonsens eine MOGIgG-Testung erfordern. Die Empfehlungen gelten für alle Patienten mit Verdacht aufZNS-Demyelinisierung bei vermuteter Autoimmunätiologie und einem entweder monophasischen oder rezidivierenden Krankheitsverlauf. Angesichts der sehr niedrigen Prä-Test-Wahrscheinlichkeit [25] wird von einem generellen MOG-IgG-Screening bei Patienten mit einem progressiven Krankheitsverlauf eher abgeraten. ๑ Tab. 2 enthält eine Reihe von Fallvignetten exemplarischer Patienten, bei denen ein hohes MOGEM-Risiko vermutet wird und die das breite Spektrum der mit diesem Syndrom verbundenen Symptome sowie die praktische Relevanz der vorgeschlagenen Kriterien veranschaulichen. In - Tab. 3 geben wir eine Reihe von Empfehlungen in Bezug auf technische Aspekte der MOGIgG-Testung (Assay-Auswahl, geeigne- 
Nervenarzt 2018 $\cdot 89: 1388-1399$ https://doi.org/10.1007/s00115-018-0607-0

(c) Der/die Autor(en) 2018

S. Jarius · F. Paul • O. Aktas · N. Asgari · R. C. Dale · J. de Seze · D. Franciotta · K. Fujihara · A. Jacob · H. J. Kim · I. Kleiter · T. Kümpfel · M. Levy · J. Palace $\cdot$ K. Ruprecht $\cdot$ A. Saiz $\cdot$ C. Trebst · B. G. Weinshenker $\cdot$ B. Wildemann

\section{MOG-Enzephalomyelitis: Internationale Empfehlungen zu Diagnose und Antikörpertestung}

\section{Zusammenfassung}

Mittels sogenannter zellbasierter Assays konnte in den vergangenen Jahren durch zahlreiche Arbeitsgruppen unabhängig eine robuste Assoziation von Immunglobulin-GAutoantikörpern gegen menschliches Voll-Längen-Myelin-OligodendrozytenGlykoprotein (MOG-lgG) mit - meist rezidivierender-Optikusneuritis (ON), Myelitis und Hirnstammenzephalitis sowie mit Fällen akuter disseminierter Enzephalomyelitis (ADEM) gezeigt werden. Die MOG-lgGpositive Enzephalomyelitis (MOG-EM) gilt den meisten Experten inzwischen als eigenständiges Krankheitsbild, das sich immunpathogenetisch sowohl von der klassischen multiplen Sklerose (MS) als auch von der Aquaporin-4(AQP4)-IgG-positiven Neuromyelitis-optica-Spektrum-Erkrankung
(NMOSD) unterscheidet. Aufgrund erheblicher Übereinstimmungen der beiden Erkrankungen in klinisch-radiologischer Hinsicht wurde die MOG-EM in der Vergangenheit oft unbeabsichtigt als MS fehldiagnostiziert. Daher werden derzeit viele Patienten mit vermuteter oder etablierter MS auf MOGIgG getestet. Das Screening von großen, nichtselektierten Kohorten auf seltene Biomarker kann jedoch den prädiktiven Wert eines Tests signifikant reduzieren. Um die damit verbundene Gefahr einer Überdiagnostizierung der MOG-EM zu verringern, werden dringend selektivere Kriterien für die Testung auf MOG-IgG benötigt. In der vorliegenden Arbeit schlagen wir, basierend auf Expertenkonsensus, Indikationen für die MOG-IgG-Testung vor. Zusätzlich wird dem Leser eine Liste mit sogenannten „red flags" an die Hand gegeben, d. h. klinischen und paraklinischen Befunden, die für die MOG-EM eher atypisch sind und Anlass sein sollten, ein positives MOG-IgG-Laborergebnis kritisch zu hinterfragen. Zusätzlich geben wir Empfehlungen zur Testmethodik, zur Probenentnahme und zur Dateninterpretation und präsentieren erstmalig Diagnosekriterien für die MOG-EM.

\section{Schlüsselwörter}

Myelin-Oligodendrozyten-Glykoprotein(MOG)-Antikörper · Konsensusempfehlungen - Diagnose $\cdot$ Antikörpertestung · Multiple Sklerose (MS) - Neuromyelitisoptica-Spektrum-Erkrankung (NMOSD) . Optikusneuritis (ON) · Myelitis

\section{MOG encephalomyelitis: international recommendations on diagnosis and antibody testing}

\section{Abstract}

Over the past few years, new-generation cellbased assays have demonstrated a robust association of autoantibodies to full-length human myelin oligodendrocyte glycoprotein (MOG-lgG) with (mostly recurrent) optic neuritis, myelitis and brainstem encephalitis, as well as with acute disseminated encephalomyelitis (ADEM)-like presentations. Most experts now consider MOG-IgG-associated encephalomyelitis (MOG-EM) a disease entity in its own right, immunopathogenetically distinct from both classic multiple sclerosis (MS) and aquaporin-4 (AQP4)-IgG-positive neuromyelitis optica spectrum disorders (NMOSD). Owing to a substantial overlap in clinicoradiological presentation, MOG-EM was often unwittingly misdiagnosed as MS in the past. Accordingly, increasing numbers of patients with suspected or established MS are currently being tested for MOG-IgG. However, screening of large unselected cohorts for rare biomarkers can significantly reduce the positive predictive value of a test. To lessen the hazard of overdiagnosing MOG-EM, which may lead to inappropriate treatment, more selective criteria for MOG-lgG testing are urgently needed. In this paper, we propose indications for MOG-lgG testing based on expert consensus. In addition, we give a list of conditions atypical for MOG-EM ("red flags") that should prompt physicians to challenge a positive MOG-IgG test result. Finally, we provide recommendations regarding assay methodology, specimen sampling and data interpretation, and propose for the first time diagnostic criteria for MOG-EM.

\section{Keywords} Myelin oligodendrocyte glycoprotein (MOG) antibodies . Consensus recommendations. Diagnosis - Antibody testing - Multiple sclerosis (MS) - Neuromyelitis optica spectrum disorders (NMOSD) - Optic neuritis (ON) Myelitis tes Probenmaterial), zur standardisierten Befundmitteilung sowie zu Fragen der Ergebnisinterpretation. Schließlich listet - Tab. 4 Befunde („red flags“) auf, von denen wir glauben, dass sie für MOGEM untypisch sind, und deren Vorliegen mithin dazu Anlass geben sollte, ein positives MOG-IgG-Testergebnis kritisch zu hinterfragen, eine Retestung zu erwägen und ggf. nach einer besseren Erklärung für das Beschwerdebild zu suchen.

In praxi erfüllen viele der nach den 2015er-Kriterien des International $\mathrm{Pa}$ - nel for NMO Diagnosis (IPND; [68]) mit einer AQP4-IgG-negativen NMOSD diagnostizierten Patienten auch die in - Tab. 1 angegebenen Kriterien für die Testung auf MOG-IgG - und sollten dann auch getestet werden. Die MOG-IgG-Testung sollte jedoch nicht auf Patienten mit AQP4-IgG-negativer NMOSD beschränkt werden. Während eine solche Beschränkung sich durch Einfachheit auszuzeichnen scheint, wäre sie aus mehreren Gründen inadäquat: (1.) Die IPND-Kriterien für AQP4-IgG- negative NMOSD erfordern eine räumliche Dissemination; dies würde viele Patienten mit MOG-EM-kompatiblen Syndromen (z. B. Patienten mit isolierter longitudinal extensiver transverser Myelitis [LETM], isolierter bilateraler ON oder isolierter Hirnstammenzephalitis) von der Testung ausschließen. (2.) Die IPND-Kriterien umfassen Magnetresonanztomographie(MRT)-Kriterien, die auf Läsionsverteilungsmustern basieren, die bei AQP4-IgG-positiver NMOSD beobachtet wurden und Unterschiede 
Tab. 1 Empfohlene Indikationen zur Testung auf MOG-IgG bei Patienten ${ }^{\#}$ mit akuten demyelinisierenden Erkrankungen des ZNS und vermuteter Autoimmunpathogenese

1. Monophasische oder rezidivierende akute Optikusneuritis, Myelitis, Hirnstammenzephalitis oder Enzephalitis oder jedwede Kombination dieser Syndrome

und

2. radiologische oder - nur bei Patienten mit Optikusneuritis - elektrophysiologische (VEP) Befunde, die mit einer demyelinisierenden Erkrankung des ZNS vereinbar sind

und

3. mindestens einer der folgenden Befunde:

$M R T$

a. Longitudinal extensive Rückenmarksläsion ( $\geq 3$ WKS, zusammenhängend) im MRT (sog. LETM) ${ }^{\mathrm{a}, \mathrm{b}}$

b. Longitudinal ausgedehnte Rückenmarksatrophie ( $\geq 3$ WKS, zusammenhängend) im MRT bei Patienten mit einem Ereignis in der Vorgeschichte, das mit einer akuten Myelitis vereinbar ist

c. Conus-medullaris-Läsion, insbesondere wenn sie zu Beginn vorhanden ist ${ }^{c}$

d. Longitudinal ausgedehnte Läsion des Sehnerven (z. B. >1/2 der Länge zwischen Sehnervkopf und Chiasma, T2 oder T1/Gd) ${ }^{\mathrm{d}}$

e. Perioptisches Gd-Enhancement während akuter $\mathrm{ON}^{\mathrm{e}}$

f. Normales supratentoriales MRT bei Patienten mit akuter ON und/oder Myelitis und/oder Hirnstammenzephalitis

g. Hirn-MRT zeigt Läsionen, aber keine periventrikuläre Läsion, die ovoid/rund ist oder mit einer inferioren Temporallappenläsion assoziiert ist, keine Dawson-Finger-artige Läsion und keine juxtakortikale U-Faser-Läsion (Matthews-Jurynczyk-Kriterien')

h. Große, konfluierende T2-Läsion, auf ADEM hinweisend

Fundoskopie

i. Prominente(s) Papillenödem/Papillitis bei akuter ON

CSF

j. Neutrophile CSF-Pleozytose ${ }^{9}$ oder Zellzahl im Liquor $>50 / \mu \mathrm{l}^{\mathrm{h}}$

k. Fehlen von liquorspezifischen OKB, egal ob bei Erst- oder Repunktion ( (gilt nur für kontinentaleuropäische Patienten)

Histopathologie

I. Primäre Demyelinisierung mit intraläsionalen Komplement- und IgG-Ablagerungen

m. Frühere Diagnose einer „Pattern-II-MS ${ }^{\prime j}$

Klinische Präsentation

n. Simultane bilaterale akute ON

o. Ungewöhnlich hohe ON-Schubfrequenz oder Erkrankung hauptsächlich durch rekurrierende ON gekennzeichnet

p. Besonders schweres Visusdefizit/Erblindung in einem oder beiden Augen während oder nach akutem Schub

q. Besonders schwere oder häufige Episoden von akuter Myelitis oder Hirnstammenzephalitis

r. Persistierende Sphinkter- und/oder Erektionsstörung nach Myelitis

s. Patienten, bei denen die Diagnose einer „ADEM“" , rezidivierenden ADEM“, „multiphasischen ADEM“ oder „ADEM-ON“ gestellt wurde

t. Akute respiratorische Insuffizienz, Bewusstseinsstörung, Verhaltensänderungen oder epileptische Anfälle (radiologische Anzeichen einer Demyelinisierung erforderlich!)

u. Erkrankungsbeginn innerhalb von 4 Tagen bis etwa 4 Wochen nach einer Impfung

v. Ätiologisch unklare, therapierefraktäre persistierende Übelkeit mit Erbrechen oder hartnäckiger Schluckauf (kompatibel mit

Area-postrema-Syndrom) ${ }^{\mathrm{a}}$

w. Gleichzeitiges Vorliegen von Teratom oder NMDAR-Enzephalitis (niedrige Evidenz ${ }^{k}$ )

Ansprechen auf Immuntherapie

x. Häufiges Wiederaufflammen der Schubsymptome nach Ende der IVMP-Therapie oder steroidabhängige Symptome' (einschließlich CRION)

y. Deutliche Zunahme der Schubrate nach Behandlung mit Interferon- $\beta$ oder Natalizumab bei Patienten mit (vermuteter) MS (niedrige Evidenz)

im AQP4-Expressionsniveau zwischen Hirnregionen widerspiegeln. AQP4 ist jedoch nicht das Zielantigen der MOGEM. Dementsprechend kann sich die Läsionsverteilung zwischen NMOSD und MOG-EM unterscheiden. Einige MOGEM-Patienten erfüllen diese Kriterien daher nicht (z. B. Patienten mit rezidivie- render bilateraler nicht-longitudinaler ON ohne Chiasmabeteiligung plus nichtNMOSD-typische Hirnläsionen; solche mit schwerer und rezidivierender nichtlongitudinal extensiver Myelitis und solche mit ADEM-artiger Präsentation mit schwerer Beteiligung des Gehirns und des Hirnstamms, aber ohne Area-
postrema-Läsion). (3.) Ferner würde eine solche Empfehlung voraussetzen, dass alle Patienten auf AQP4-IgG getestet werden, bevor sie auf MOG-IgG getestet werden können, was die Diagnose und Behandlung unnötig verzögern könnte. (4.) Neben dem zu erwartenden erheblichen Verlust an Sensitivität und Spezifität 


\section{Konsensuspapiere}

Tab. 1 (Fortsetzung)

ADEM Akute disseminierte Enzephalomyelitis, ADEM-ON ADEM mit rekurrierender ON, $A Q P 4$ Aquaporin-4, CRION chronische rezidivierende entzündliche Optikusneuropathie, CSF Cerebrospinalfü̈ssigkeit, EM Enzephalomyelitis, Gd Gadolinium, IA Immunadsorption, IgG Immunglobulin G, IQR Interquartilsabstand, IVMP intravenöses Methylprednisolon, LETM longitudinal extensive transverse Myelitis, MOG Myelin-Oligodendrozyten-Glykoprotein, MRT Magnetresonanztomographie, MS multiple Sklerose, NMDAR N-Methyl-D-Aspartat-Rezeptor, NMO Neuromyelitis optica, NMOSD "neuromyelitis optica spectrum disorder" (Neuromyelitis-optica-Spektrum-Erkrankung), OKB oligoklonale lgG-Banden, ON Optikusneuritis, PEX Plasmaaustausch, RRMS schubförmig remittierende MS, VEP visuell evozierte Potentiale, WKS Wirbelkörpersegmente, ZNS Zentralnervensystem

${ }^{*}$ N.b.: Die folgenden Empfehlungen sind in erster Linie für Erwachsene und Jugendliche gedacht. Die Indikationsstellung für eine MOG-lgG-Testung bei Kleinkindern kann weniger streng erfolgen als bei Erwachsenen, da MOG-EM bei kleinen Kindern mit erworbenen demyelinisierenden Erkrankungen (bis zu 70\%; abnehmende Frequenz mit zunehmendem Alter) signifikant häufiger auftritt als bei Erwachsenen ( $<1 \%$ in westlichen Ländern; wahrscheinlich $<5 \%$ in Japan und anderen asiatischen Ländern aufgrund der generell niedrigeren MS-Prävalenz) und die in der Einleitung beschriebenen Risiken eines Screenings auf MOG-IgG in dieser Altersgruppe in der Folge von geringerer Relevanz sind. ${ }^{2}$ Wenn Kosten eine Rolle spielen und der Patient sich in Remission befindet: zuerst AQP4-IgG testen, da in diesem Zustand häufiger als MOG-IgG. Wenn die Krankheit aktiv ist, schnelle Entscheidungen erfordert oder Kosten keine wesentliche Rolle spielen: parallel AQP4-lgG und MOG-IgG testen. ${ }^{b}$ Langstreckige Myelonläsionen ( $\geq 3$ WKS) kommen sowohl bei MOG-EM als auch bei AQP4-NMOSD häufig vor, sind bei MS jedoch äußerst selten. Cave: Konfluierende spinale MS-Läsionen können eine LETM imitieren! Nota bene: Kurze Läsionen schließen per se eine MOG-EM nicht aus. Das spinale MRT zeigt bei etwa 44-52\% aller MOG-EM-Patienten [23, 37] und etwa 15\% aller AQP4-NMOSD-Patienten [26] mindestens einmal im Lauf der Erkrankung kurze Läsionen. Die Läsionslänge kann auch vom MRT-Timing abhängen, wobei kürzere Läsionen detektiert werden, wenn das MRT früh in der Entwicklung der akuten Myelitis oder in klinischer Remission durchgeführt wurde. Sowohl axiale als auch sagittale Ebenen sollten verwendet werden, um das Ausmaß der Läsion zu beurteilen. Langstreckige Rückenmarksläsionen sind auch bei Kindern mit MOG-IgG-positiver Myelitis häufig (bei Krankheitsbeginn bei 32/40 Kindern mit anderen Manifestationen als isolierter ON in [4]). 'Beobachtet bei 6/8 Patienten in [33] (bei Erkrankungsbeginn); 4/6 in [58]; 4/11 in [14]; 3/12 in [65]; 5/26 (lumbales MRT nicht bei allen durchgeführt) in [23] und bei 13/40 pädiatrischen Patienten (bei Erkrankungsbeginn) mit anderer Manifestation als ON in [4]. 'Ramanathan et al. (2015) berichteten über eine mediane Sehnervläsionslänge von 23,1 mm (IQR 18-33 mm) bei MOG-IgG-assoziierter ON ( $N=19)$; im Vergleich hierzu betrug die mediane Läsionslänge bei MS-assoziierter ON 9,9 mm (IQR 6,6-19,8 mm) in derselben Studie $(N=13 ;$ [52]) und 10,5 mm in einer zweiten, unabhängigen Studie ( $N=26$; [41]). Neuere Daten legen nahe, dass eine Beteiligung (T2, T1/Gd oder Schwellung des Sehnerven) von >6/12 Sehbahnsegmenten (anteriores orbitales Segment $R / L$, posteriores orbitales R/L, kanalikuläres R/L, intrakraniales R/L, Chiasma rechte/linke Hälfte, Tractus opticus rechts/links) mit erhöhten Prä-Test-Odds für MOG-IgG assoziiert ist (beobachtet bei 6/19 [32\%] MOG-IgG-positiven ON-Patienten, aber in keinem von 13 [0\%] MS-ON-Patienten; [52]). Auch eine weitere Studie fand longitudinal ausgedehnte Läsionen über mindestens 4 von 5 Segmenten (anteriores intraorbitales Segment, posteriores intraorbitales Segment, kanalikulär, intrakraniell, chiasmal) bei $\geq 50 \%$ der MOG-IgG-positiven Patienten [1]. Im Gegensatz dazu erstreckten sich Läsionen bei MS-assoziierter ON nur über $1(70 \%)$ oder $2(30 \%)$ von 9 Segmenten (intraorbitales Segment R/L, kanalikuläres R/L, intrakraniales R/L, chiasmal, rechte/linke Seite des optischen Trakts) in [41] und eine mittlere Ausdehnung von nur 2,2/10 Segmenten (orbital R/L, kanalikulär R/L, intrakraniell R/L, Chiasma rechte/linke Hälfte, Tractus opticus rechts/links) wurde bei MS-ON beobachtet in [62]. Läsionen, deren Länge mehr als der Hälfte des Abstands zwischen Sehnervenkopf und Chiasma entsprach, fanden sich auch bei 3 von 3 Patienten in [5] und bei 6/10 (60\%) in [23]. Schließlich zeigten 9/10 (90\%) Han-Patienten mit MOG-ON eine Beteiligung aller drei Segmente des prächiasmalen Sehnervs (intraorbital, kanalikulär, intrakranial) in [71], von denen 6 zusätzlich eine Chiasma- und/oder Optikusbeteiligung aufwiesen. ${ }^{e}$ Vorliegend bei 11/28 Patienten während akuter ON in [23], bei 6/18 in [31] und bei 6/8 in [71], aber üblicherweise nicht

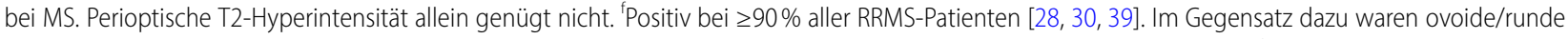
Läsionen, die an einen lateralen Ventrikel angrenzen, Läsionen, die an einen lateralen Ventrikel angrenzen und mit einer inferioren Temporallappenläsion assoziiert sind, und Dawson-Finger-artige Läsionen bei 21/21 (100\%) MOG-lgG-positiven Patienten in einer gemischt adulten $(N=15)$ und pädiatrischen $(N=6)$ Kohorte nicht nachweisbar [28, 30] und juxtakortikale U-Faser-Läsionen waren bei 20/21 (95,2\%) nicht nachweisbar. Kürzlich wurde das Fehlen von Dawson-Finger-Läsionen bei MOG-IgG-positiven Patienten auch in einer ausschließlich pädiatrischen Kohorte bestätigt (abwesend in 68/69 [98\%] Fällen; der einzige Patient, der Dawson-Finger-Läsionen aufwies, hatte eine typische MS und war in der Wiederholungstestung negativ für MOG-IgG); U-Faser-Läsionen fehlten in 65/69 (94,2\%) MOG-IgG-positiven pädiatrischen Patienten in derselben Studie [4]. ${ }^{9}$ Mindestens einmalig bei $64 \%$ der Patienten mit Pleozytose ([23]; Median 22\% aller Leukozyten im Liquor; Spannweite 3-69\%), aber typischerweise nicht vorhanden bei MS. N.b.: Neutrophile Pleozytose wird auch

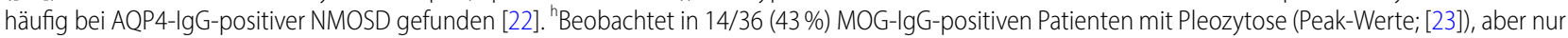
selten bei Patienten mit MS (<2\% nach [54]; 1/71 Patienten $\geq 15$ Jahre (Spannweite 15-29 Jahre) in [55]). 'Oligoklonale Banden (OKB) werden bei bis zu $98 \%$ der MS-Patienten in Mittel- und Nordeuropa beobachtet [55], waren aber nur in 12 bzw. 13 \% bei Patienten mit MOG-EM in zwei neueren mitteleuropäischen Studien nachweisbar [23, 29]. In einer kürzlich durchgeführten multizentrischen Studie wiesen viele MOG-EM-Patienten, bei denen zuvor fälschlich eine MS diagnostiziert worden war, keine OKB auf [23]. Positive OKB alleine schließen eine MOG-EM jedoch nicht aus [23]. Es ist zu beachten, dass die Häufigkeit von OKB bei MS niedriger sein könnte bei asiatischen Patienten (z. B. 40-80\% in Japan) sowie in einigen Regionen in Europa wie Sardinien (84\% in einer neueren Studie [11]), möglicherweise in Abhängigkeit von genetischen Faktoren. „Keine liquorspezifischen OKB“ bezieht sich auf das Vorhandensein der OKB-Muster 1 (keine OKB im Liquor), 4 (spiegelbildliche Banden in Liquor und Serum ohne zusätzliche IgG-Banden, die ausschließlich im CSF vorhanden sind) und 5 (monoklonale lgG-Bande sowohl im CSF als auch im Serum; [2]). 'Bei einigen Patienten, bei denen in der Vergangenheit aufgrund des histologischen Nachweises sog. „Pattern-II-MS“-Läsionen (durch IgG- und Komplementablagerungen charakterisiert) eine MS diagnostiziert wurde, wurden später retrospektiv MOG-IgG-Antikörper gefunden [21, 35, 61]. Dies legt nahe, dass die aktuell gültigen histopathologischen Kriterien nicht ausreichend spezifisch sein könnten, um zwischen MS und MOG-EM zu unterscheiden. ${ }^{k}$ Patienten mit Teratom und positivem MOG-IgG-Serostatus wurden bisher in zwei Kohorten identifiziert (2/74; 3\%; [7, 20, 23]). Die Expression von CNPase, einem Oligodendrozytenmarker, wurde in reifen Teratomen beschrieben; Oligodendrogliome können in reifen Teratomen auftreten. Zusätzliche Tests auf NMDAR-Antikörper werden bei Patienten mit Teratom und neurologischen Symptomen dringend empfohlen [63]. Aktuelle, vorläufige Berichte deuten darauf hin, dass MOG-EM und NMDAR-Enzephalitis gelegentlich koexistieren können [10]. 'Wiederauftreten der Symptome nach Ausschleichen einer oralen Steroidtherapie [6, 23, 45, 49, 53] 
Tab. 2 Fallvignetten von Patienten mit hohem Risiko für MOG-IgG-Seropositivität (Beispiele)

Beispiel 1

35-jährige Frau, die sich mit bilateraler akuter ON vorstellt. Vorübergehende beidseitige Erblindung; Fundoskopie zeigt Papillenödem; Lumbalpunktion erbringt Nachweis einer lymphomonozytären Pleozytose mit 10\% Neutrophilen und negativen OKB; kraniales MRT bis auf Optikusläsion mit perioptischer Gd-Anreicherung unauffällig; Wiederaufflackern der Beschwerden nach Ausschleichen der oralen Steroidbehandlung; später rezidivierende Attacken, Stabilisierung unter Rituximab

Beispiel 2

40-jährige Frau, zwei Episoden akuter, OKB-negativer Myelitis. Spinales MRT zeigt während der ersten Episode eine isolierte kurze Rückenmarksläsion und eine longitudinal extensive Rückenmarksläsion während der zweiten Episode; kraniales MRT auffällig, aber keine Dawson-Finger-artigen Läsionen, keine juxtakortikalen U-Faser-Läsionen und keine Läsionen, die in Nachbarschaft zu den Ventrikeln liegen und entweder ovoid/rund oder mit einer inferioren Temporallappenläsion assoziiert sind [30, 39]; Aufflackern von Myelitissymptomen nach Absetzen der intravenösen Steroidbehandlung, gutes Ansprechen auf PEX

Beispiel 3

Junger Mann, in der Vergangenheit "OKB-negative RRMS" diagnostiziert. Überwiegend ON- und Myelitis-Attacken; Konusläsion mit schwerer erektiler und Sphinkterstörung nach erster Myelitis; longitudinal extensive Sehnervenläsion mit Beteiligung des Chiasma opticum; Erhöhung der Schubrate unter Behandlung mit Interferon- $\beta$, aber Stabilisierung unter Rituximab

Beispiel 4

42-jährige Frau, die sich mit unvollständiger, schmerzhafter Tetraparese vorstellt. Frühere Diagnose „RRMS“; positive OKB. Spinales MRT zeigt eine zusammenhängende Läsion von C3 bis T1; negative Serologie für AQP4-lgG

Beispiel 5

ADEM-ähnliche Präsentation mit großen Läsionen der weißen Substanz und Bewusstseinsstörung, Hirnstammläsionen und Beteiligung des gesamten Rückenmarks bei einer 25 Jahre alten Frau; Beginn 3 Wochen nach einer Impfung

Beispiel 6

39-jähriger Mann mit simultaner unilateraler ON und LETM mit Fortsetzung in die Medulla oblongata. Liquorpleozytose ( 90 Zellen/ $\mu$ l) mit $5 \%$ Neutrophilen; keine CSF-restringierten OKB; negativer AQP4-IgG-Serostatus

Beispiel 7

Junge Frau, die sich mit rezidivierender und steroidabhängiger isolierter ON vorstellt, die bislang als „CRION“ klassifiziert wurde; normales MRT des Gehirns

Beispiel 8

Junger Mann mit akuter Enzephalitis und epileptischen Anfällen. Das kraniale MRT zeigt kortikale sowie subkortikale Läsionen der weißen Substanz; gutes Ansprechen auf Steroide; kein Hinweis auf virale und autoimmune Enzephalitis anderer Ursache

ADEM Akute disseminierte Enzephalomyelitis, AQP4 Aquaporin-4, ZNS Zentralnervensystem, CRION chronische rezidivierende entzündliche Optikusneuropathie, CSF Cerebrospinalflüssigkeit, EM Enzephalomyelitis, Gd Gadolinium, IA Immunadsorption, IgG Immunglobulin G, LETM longitudinal extensive transverse Myelitis, MOG Myelin-Oligodendrozyten-Glykoprotein, MRT Magnetresonanztomographie, MS multiple Sklerose, NMO Neuromyelitis optica, OKB oligoklonale lgG-Banden, ON Optikusneuritis, PEX Plasmaaustausch, RRMS schubförmig remittierende MS

wäre die Heranziehung von NMOSDKriterien zur Diagnose einer MOG-EM für Nichtexperten verwirrend, handelt es sich doch um verschiedene Erkrankungen mit unterschiedlichen Zielantigenen (AQP4 vs. MOG), unterschiedlicher Pathophysiologie (Astrozytopathie vs. Oligodendrozytopathie) und nur teilweise überlappenden klinischen Spektren. (5.) Die Kriterien für AQP4-IgGseronegative NMOSD erfordern zudem den Ausschluss anderer Diagnosen; dies hätte einen logischen Widerspruch zur Folge, da ein negatives Testergebnis für MOG-IgG zur Bedingung für die Durchführung des MOG-IgG-Tests würde.

Wäre es eine Lösung, die MOGIgG-Testung stattdessen auf Patienten mit AQP4-IgG-negativer NMO gemäß Wingerchuks 2006er-Kriterien [69] zu beschränken? Da diese Kriterien sowohl eine $\mathrm{ON}$ als auch eine Myelitis aktuell oder in der Vorgeschichte erfordern, würde dies wiederum dazu führen, dass eine erhebliche Anzahl von Patienten mit hohem MOG-EM-Risiko nicht getestet würde. Ein solcher Ansatz wäre also ebenfalls nicht sinnvoll. Zu beachten ist in diesem Zusammenhang, dass die Testung aller Patienten mit seronegativer NMO nach Wingerchuk 2006 auf MOGIgG bereits durch unsere Empfehlung abgedeckt ist, alle Patienten mit LETM auf MOG-IgG zu testen (s. • Tab. 1), da das Vorliegen einer LETM bei AQP4IgG-negativen Patienten conditio sine qua non für die Stellung der Diagnose einer NMO nach den 2006er Kriterien ist.

Wir schlagen stattdessen vor, die Indikation für eine Testung auf MOG-IgG bei Patienten mit Verdacht auf eine ZNSDemyelinisierung auf das Vorliegen spezifischer klinischer und paraklinischer Befunde zu stützen, die typisch für die MOG-EM und/oder atypisch für die konventionelle MS sind (s. - Tab. 1).

Während des Konsensfindungsprozesses wurden Bedenken hinsichtlich der Aufnahme der folgenden behandlungsbezogenen Indikationen für die MOGIgG-Testung in - Tab. 1 geäußert:

a. Besonders gutes Ansprechen auf antikörperdepletierende Therapien

(PEX, Immunadsorption [IA])

b. Besonders gutes Ansprechen auf

B-Zell-depletierende Therapien

(Rituximab, Ocrelizumab, Ofatumu-

mab), aber Rückfall unmittelbar nach dem Wiederauftreten von B-Zellen

Einige Mitglieder des Panels verwiesen darauf, dass auch bei klassischer MS ein gutes Ansprechen auf PEX, IA oder B-Zell-Depletion vorkommen kann. Es wurde jedoch Konsensus erzielt, dass, wenn zusätzlich zu einer der in • Tab. 1 aufgeführten Indikationen vorliegend, ein gutes Ansprechen auf antikörperoder B-Zell-depletierende Therapien oder IVIG die Prä-Test-Wahrscheinlichkeit für das Vorliegen einer MOG-EM weiter erhöht und somit die Entscheidung für eine Testung auf MOG-IgG unterstützt.

Unter Berücksichtigung der Tatsache, dass die MOG-IgG-Serumspiegel einerseits von Krankheitsaktivität (mit hö- 


\section{Assay-Typen}

Zellbasierte Assays (IFT/FACS): empfohlen (aktueller Goldstandard); muss humanes Volllängen-MOG als Zielantigen verwenden; Verwendung eines Fc-spezifischen (oder lgG1-spezifischen [66]) Sekundärantikörpers dringend empfohlen, um eine Kreuzreaktivität mit (spezifisch oder nichtspezifisch bindenden) IgM- und IgA-Antikörpern zu vermeiden [57,66]

Immunhistochemie: derzeit nicht empfohlen (weniger empfindlich als zellbasierte Assays, begrenzte Daten zur Spezifität verfügbar [48, 57]; Sensitivität von Art des Spendergewebes abhängig [48]); falls verwendet, sind Fc-spezifische Sekundärantikörper, die gegen Gewebedonor-lgG adsorbiert sind, erforderlich, um eine Kreuzreaktivität mit IgM und IgA oder mit gewebegebundenem Donor-lgG zu vermeiden

Peptidbasierter ELISA, Western Blot: ungenügend spezifisch, obsolet

Biomaterial

Serum: empfohlen (Probenmaterial der Wahl); Versand bei $4^{\circ} \mathrm{C}$ oder auf Trockeneis ratsam, wenn die Proben nicht innerhalb von 1 bis 2 Tagen eintreffen

Liquor: in der Regel nicht erforderlich, da MOG-IgG meist extrathekal produziert wird, was zu einem niedrigeren CSF- als Serumtiter führt [24]; möglicherweise in seltenen, ausgewählten Fällen hilfreich (z. B. starker Hintergrund durch koexistierende, nicht MOG-spezifische Serumantikörper); Versand bei $4^{\circ} \mathrm{C}$ oder auf Trockeneis ratsam

Immunglobulinklassen

Testung aufMOG-IgG: empfohlen

Testung auf MOG-IgM und/oder MOG-IgA: derzeit nicht empfohlen; zusätzliche MOG-IgM- und MOG-IgA-Antikörper wurden bei einigen MOG-IgG-positiven Patienten beschrieben [24, 36]; die klinische Relevanz isolierter MOG-IgM- oder MOG-IgA-Ergebnisse ist nicht bekannt; das Testen auf Antikörper der IgM-Klasse erfordert die Entfernung von Gesamt-IgG aus der Probe, um sowohl falsch-negative (aufgrund von hochaffinem, IgM-verdrängendem IgG) als auch falsch-positive (aufgrund von IgM-anti-lgG-Fc-Rheumafaktoren) Ergebnisse zu vermeiden [19]

\section{Befundbericht}

In Laborbericht und Arztbrief dokumentiert werden sollten grundsätzlich: nachgewiesene Immunglobulinklasse, Testmethode, antigenes Substrat, verwendetes Biomaterial, Titer/Konzentration/Einheiten, Assay-spezifische Grenzwerte und durchführendes Labor (z. B. „Serum MOG-IgG 1: 1280 [Cut-off $\geq 1: 160^{\text {a }}$; Nachweismethode: Live-CBA, Labor: Universitätsklinikum Heidelberg; Antigen: humanes Volllängen-MOG“)

\section{Dateninterpretation}

Wie bei allen Labortests sollten positive Testergebnisse immer im Kontext der Gesamtpräsentation interpretiert werden; wenn "red flags" gemäß der Definition in - Tab. 4 vorhanden sind, wird eine Retestung der ursprünglich positiv befundeten Serumprobe (oder, falls nicht mehr verfügbar, zumindest der Test einer Folgeserumprobe) empfohlen; um das Risiko zu mindern, falsch-positive Ergebnisse aufgrund von methodeninhärenten Fehlern zu reproduzieren, ist die Verwendung eines zweiten (und, im Fall von abweichenden Ergebnissen, dritten), methodologisch unterschiedlichen zellbasierten Tests ratsam; im Zweifelsfall Konsultation eines spezialisierten Zentrums erwägen

\section{Zeitpunkt der Probenentnahme}

Die MOG-IgG-Serumkonzentration schwankt im zeitlichen Verlauf, u. a. in Abhängigkeit von Krankheitsaktivität (mit meist höheren medianen Konzentrationen während akuter Schübe) und Behandlungsstatus (mit möglicherweise niedrigeren Konzentrationen unter Immunsuppression), und kann nach Plasmapherese unter die Nachweisgrenze absinken [23]; wenn MOG-IgG bei Ersttestung negativ ist, aber eine MOG-EM klinisch weiterhin vermutet wird, ist eine Retestung insbesondere während akuter Attacken und/oder behandlungsfreier Intervalle bzw. 1-3 Monate nach PEX/IA (oder $\mathrm{IVIG}^{\mathrm{b}}$ ) ratsam - N.b.: Ein dauerhaftes Verschwinden des Antikörpers wurde bei Kindern, aber gelegentlich auch bei Erwachsenen beobachtet und war in diesen Fällen mit einem monophasischen Krankheitsverlauf assoziiert [9, 14, 20, 23, 24, 50]

CBA Zellbasierter Assay, CSF Cerebrospinalfüssigkeit, ELISA enzymgekoppelter Immunosorbent-Assay, EM Enzephalomyelitis, FACS fluoreszenzaktivierte Zellsortierung, IA Immunadsorption, IgG/A/M Immunglobulin G/A/M, IFT indirekter Fluoreszenztest, IVIG intravenöse Immunglobuline, MOG Myelin-Oligodendrozyten-Glykoprotein, PEX Plasmaaustausch

${ }^{a}$ Cave: Bei dem hier angegebenen Cut-off handelt es sich um ein Beispiel; Cut-off-Werte sind immer Assay-abhängig

${ }^{b}$ Generell kann eine Vorbehandlung mit IVIG sowohl falsch-negative als auch falsch-positive Ergebnisse in serologischen Tests verursachen [3, 12, 17]; ob IVIG als Störfaktor in den derzeit zum Nachweis von MOG-IgG verwendeten Immunoassays von Relevanz sind, ist Gegenstand laufender Untersuchungen

heren Konzentrationen während akuter Attacken) und Behandlungsstatus (mit niedrigeren Konzentrationen unter Immunsuppression) sowie andererseits von der Testsensitivität abhängen, empfehlen wir in Fällen, in denen MOG-IgG bei der ersten Untersuchung negativ war, aber eine MOG-EM weiterhin vermutet wird, eine erneute Testung während akuter Attacken und/oder während behandlungsfreier Intervalle [23].

Über die Nützlichkeit regelmäßiger MOG-IgG-Titer-Kontrollen liegen nur spärliche Daten vor. In einer kürzlich veröffentlichten Studie fanden sich signifikant höhere mediane MOG-IgGTiter im akuten Schub [24]. Regelmäßige MOG-IgG-Untersuchungen im Verlauf könnten daher theoretisch eine potenziell vielversprechende Methode zur Vorhersage von Schüben und zur Überwachung der Wirksamkeit der Behandlung sein. Es gibt jedoch zahlreiche Einschränkungen: Während die Titer im akuten Schub im Median bei >1:2560 lagen [24], wiesen einige Patienten auch während akuter Attacken relativ niedrige Titer auf und fanden sich umgekehrt bei einigen Patienten hohe Titer auch in Remission, was nahe legt, dass zusätzliche Faktoren wie z.B. eine Schädigung der Blut-Hirn-Schranke, T-Zell-Aktivierung oder Unterschiede in Antikörperaffinität oder komplementaktivierender Aktivität der Antikörper involviert sind. Ein interoder auch nur intraindividuell gültiger Cut-off-Titer, ab dem ein neuer Schub als imminent zu betrachten wäre, kann daher nicht sicher festgelegt werden [24]. 
Tab. 4 „Red flags": Befunde, die, wenn vorliegend, Anlass geben sollten, ein positives MOG-IgG-Testergebnis zu verifizieren (Retestung erwägen, idealerweise mittels eines alternativen, d. h. methodisch nicht identischen, zellbasierten Assays; falls nicht verfügbar oder im Falle diskrepanter Ergebnisse Vorstellung in spezialisiertem Zentrum in Betracht ziehen)

\section{Krankheitsverlauf}

Kontinuierliche, schubunabhängige, chronisch fortschreitende Verschlechterung (sehr selten bei MOG-IgG-positiven Patienten [23]), einschließlich SPMS (insbesondere SPMS ohne Schübe) und PPMS ${ }^{\mathrm{a}}$

Plötzliches Auftreten der Symptome, z. B. <4 h vom Beginn bis zum Maximum (ischämische Ursache erwägen), oder kontinuierliche Verschlechterung der Symptome über Wochen (Tumor, Sarkoidose etc. erwägen)

MRT

Dawson-Finger-artige Läsion oder Läsion neben einem lateralen Ventrikel, die ovoid/rund ist oder mit einer inferioren Temporallappenläsion assoziiert ist

Aktivität im kranialen MRT zwischen klinisch manifesten Schüben mit stiller Zunahme der Läsionslast (begrenzte Evidenz)

CSF

Bi- oder trispezifische MRZ-Reaktion ${ }^{\mathrm{b}}$ (MS erwägen)

Serologie

MOG-IgG-Titer am oder nur knapp über dem Assay-spezifischen Cut-off ; insbesondere, aber nicht ausschließlich, wenn das klinische Bild atypisch ist MOG-IgM und/oder MOG-IgA positiv, aber MOG-IgG negativ (klinische Signifikanz unbekannt)

MOG-IgG-Positivität nur im Liquor, nicht im Serum ${ }^{\text {d }}$ (MOG-IgG wird typischerweise extrathekal produziert)

Gleichzeitiges Vorliegen von AQP4-IgG und MOG-IgG („Doppelpositivität“; extrem selten; Wiederholung beider Tests empfohlen) ${ }^{e}$

Sonstiges

Klinische oder paraklinische Befunde, die auf andere Diagnosen als MOG-EM, NMOSD oder MS hinweisen (z. B. Neurotuberkulose, Neuroborreliose, Neurosyphilis, Neurosarkoidose, Behçet-Syndrom, funikuläre Myelose, Lebersche hereditäre Optikusneuropathie, Vaskulitis, ZNS-Lymphom, Gliomatosis cerebri, paraneoplastische neurologische Syndrome ${ }^{f}$, PRES, PML, Hinweise auf eine ZNS-Infektion ${ }^{9}$ )

Kombinierte zentrale und periphere Demyelinisierung ([8]; MOG wird im peripheren Nervensystem nicht exprimiert)

ADEM Akute disseminierte Enzephalomyelitis, AQP4 Aquaporin-4, CSF Cerebrospinalfüssigkeit, EM Enzephalomyelitis, IgG/A/M Immunglobulin G/A/M, IPND International Panel for NMO Diagnosis, MOG Myelin-Oligodendrozyten-Glykoprotein, MRZ-Reaktion Masern-, Röteln- und Zoster-Virus-Reaktion, MS multiple Sklerose, NMDAR N-Methyl-D-Aspartat-Rezeptor, NMO Neuromyelitis optica, NMOSD "neuromyelitis optica spectrum disorder" (Neuromyelitis-optica-Spektrum-Erkrankung), OKB oligoklonale IgG-Banden, PPMS primär progrediente MS, PML progressive multifokale Leukoenzephalopathie, PRES posteriores reversibles Enzephalopathie-Syndrom, SPMS sekundär progrediente MS, ZNS Zentralnervensystem

aEine aktuelle Studie fand unter 290 Patienten mit PPMS $(n=174)$ oder SPMS $(n=116)$ nur einen einzigen grenzwertig positiven Fall [25]

${ }^{b}$ Masern(M)-, Röteln(R)- und Zoster-Virus(Z)-Reaktion: intrathekale Synthese gegen mindestens zwei dieser drei viralen Agenzien (d. h. gegen $M+R, M+Z$, $\mathrm{R}+\mathrm{Z}$ oder $\mathrm{M}+\mathrm{R}+\mathrm{Z}$ ); Teil der polyspezifischen, intrathekalen humoralen Immunreaktion bei MS; bei etwa $70 \%$ der MS-Patienten, aber nicht oder nur sehr selten bei MOG- oder AQP4-IgG-positiven Patienten nachweisbar (MOG-EM: 0/11; NMO: 1/42; „ADEM“: 1/26; [18, 23, 56])

'Außer bei Patienten, die zuvor deutlich über dem Assay-spezifischen Cut-off positiv waren; in solchen Fällen können niedrige oder grenzwertige MOG-IgGTiter einen genuinen (spontanen oder behandlungsbedingten) Abfall der Antikörperkonzentration widerspiegeln

'Kann in den seltenen Fällen gültig sein, in denen gleichzeitig vorhandene Serumautoantikörper die Serumanalyse, nicht aber die CSF-Analyse beeinträchtigen (falsch-negativer Serumtest)

'Wenn in einem zweiten Test bestätigt und die IPND-Kriterien für NMOSD erfüllt sind, muss von einer Koexistenz von MOG-EM und AQP4-NMOSD ausgegangen werden

'Eine gelegentliche Koinzidenz von MOG-EM und NMDAR-Enzephalitis wurde beschrieben [10]; bei Vorliegen einer gleichzeitigen NMDAR-Enzephalitis muss ein Teratom ausgeschlossen werden [63]

${ }^{9}$ Cave: CSF-Befunde bei MOG-EM (wie auch bei AQP4-NMOSD) können eine ZNS-Infektion imitieren mit neutrophiler Pleozytose, gestörter Blut-CSF-Schrankenfunktion und fehlenden OKB $[22,23,26]$. Die Liquorzellzahl bei MOG-EM lag in einer neueren europäischen Studie zwischen 6 und 306 Zellen/ $\mu$ l (Median 33 Zellen/ $\mu$ l; Interquartilsabstand 13-125 Zellen/ $\mu$ l); $\geq 100$ Zellen/ $\mu$ l waren mindestens einmal bei 9/32 (28,1\%) Patienten vorhanden; neutrophile Granulozyten waren mindestens einmal nachweisbar bei 9/14 (64,3\%) Patienten mit Pleozytose und verfügbaren Daten (Median 22\% aller weißen Zellen; Bereich 3-69\%)

hKann in den seltenen Fällen, in denen MOG-EM und mit dieser nicht in Zusammenhang stehende periphere Neuropathien anderer Ursache koexistieren, wahr-positiv sein

Darüber hinaus könnten Behandlungseffekte eine Rolle spielen. Schließlich ist derzeit unklar, in welchen zeitlichen Abständen Verlaufsuntersuchungen erfolgen müssten, um drohende Schübe rechtzeitig zu erkennen. Basierend auf Erfahrungen aus Studien zur AQP4IgG-positiven NMOSD, bei denen die Serumantikörperspiegel erst kurz vor Schubbeginn ansteigen [16], könnten sehr enge Testintervalle erforderlich sein. Dies würde ein Langzeit-Monitoring sowohl teuer als auch in praktischer Hinsicht schwierig durchführbar machen. Dementsprechend kann derzeit keine generelle Empfehlung zur regelmäßigen Überwachung der MOG-IgGTiter zur Schubvorhersage oder Behandlungsüberwachung gegeben werden.
Bei einigen Patienten kann MOG-IgG im Laufe der Zeit spontan oder therapieinduziert unter die Nachweisgrenze fallen $[9,14,24,50]$. Interessanterweise hatten viele dieser Patienten eine monophasische Erkrankung. Im Gegensatz dazu war in einer aktuellen Studie MOGIgG bei allen Patienten mit einem rezidivierenden Krankheitsverlauf und verfügbaren Follow-up-Proben $(n=18)$ auch 
bei der letzten Follow-up-Untersuchung (mittleres Intervall 33 Monate seit Erstuntersuchung; maximale Nachbeobachtungszeit 10 Jahre) weiterhin nachweisbar [24]. Das Verschwinden von MOGIgG nach dem ersten Schub könnte daher prognostische Bedeutung haben, und ein erneuter Test von MOG-IgG-positiven Patienten 6-12 Monate nach der ersten Attacke könnte folglich prognostisch und therapeutisch von Nutzen sein. Es gibt jedoch einige Einschränkungen: Die meisten der berichteten monophasischen Patienten waren Kinder oder Jugendliche und die meisten hatten eine ADEM. Darüber hinaus liegen $\mathrm{zu}$ den meisten Fällen keine publizierten Langzeitdaten vor. Letzteres ist wichtig, da die Titer nach einer Behandlung mit Steroiden, PEX oder IA (oder sogar spontan) unter die Nachweisgrenze fallen und in einem späteren Krankheitsstadium wieder ansteigen können; dementsprechend wurde eine transiente Serokonversion auch bei einigen Patienten mit rezidivierender Erkrankung beobachtet [24, 50, 60]. Es wäre daher problematisch, langfristige Behandlungsentscheidungen allein darauf zu stützen, ob MOG-IgG nach dem ersten Schub unter die Nachweisgrenze sinkt oder nicht. Wenn eine Langzeitbehandlung mit Immunsuppressiva oder oralen Steroiden aufgrund beobachteter Serokonversion (im Sinne eines Absinkens des MOG-IgG-Titers unter die Nachweisgrenze) beendet wird, wird eine strenge Überwachung des MOG-IgGSerostatus des Patienten dringend empfohlen, um die Seronegativität auch im Langzeitverlauf zu bestätigen. Vor der Stellung der Diagnose einer „monophasischen MOG-EM" und damit vor einer Entscheidung gegen eine Langzeitbehandlung sollte auch berücksichtigt werden, dass bei Patienten mit schubförmiger MOG-EM das Intervall zwischen erstem und zweitem Schub erheblich variiert und es in einigen Fällen erst nach mehreren Jahren zu einem zweiten Schub kommt [23].

\section{Diagnosekriterien für die MOG-Enzephalomyelitis}

In Hinblick auf künftige Studien sind diagnostische Kriterien für die MOG-EM wünschenswert. Es wurden jedoch bisher keine spezifischen klinischen oder radiologischen Befunde (mit Ausnahme der allgemeinen Anforderung einer demyelinisierenden ZNS-Läsion) identifiziert, die bei allen MOG-IgG-positiven Patienten vorliegen und somit eine diagnostische conditio sine qua non darstellen würden. Es wurden verschiedene MRT-Befundkonstellationen vorgeschlagen, die für eine MOG-EM typisch sein sollen; dies muss jedoch in unabhängigen und größeren Kohorten bestätigt werden [28, 30]. Wir schlagen vor, dass die MOG-EM vorerst bei allen Patienten diagnostiziert werden sollte, die alle der folgenden drei Kriterien erfüllen:

1. Monophasische oder rezidivierende akute ON, Myelitis, Hirnstammenzephalitis oder Enzephalitis oder eine Kombination dieser Syndrome

2. MRT-oder, nur bei Patienten mit isolierter ON, elektrophysiologische (visuell evozierte Potentiale) Befunde, die mit einer Demyelinisierung des ZNS kompatibel sind

3. Seropositivität für MOG-IgG, nachgewiesen mittels eines zellbasierten Assays unter Verwendung von humanem Volllängen-MOG als Zielantigen

Bei Patienten mit Befunden, die in - Tab. 4 als „red flags“ ausgewiesen sind, und bei denen der positive MOG-IgGBefund noch nicht mittels eines zweiten (und gegebenenfalls dritten) zellbasierten Assays bestätigt wurde, wird empfohlen, insbesondere im Kontext von Studien die Diagnose „mögliche MOGEM“ zu stellen.

\section{Limitationen und "caveats"}

Alle hier vorgelegten Empfehlungen basieren notwendigerweise auf Expertenkonsens, da systematische und prospektive Studien bislang fehlen. Darüber hinaus soll als allgemeine Einschränkung betont werden, dass vor Diagnosestellung alle verfügbaren Informationen, einschließlich klinischer, radiologischer, elektrophysiologischer und Labordaten, berücksichtigt und Differenzialdiagnosen, von denen einige in $\square$ Tab. 4 aufgeführt sind, unbedingt ausgeschlossen werden müssen. Die meisten Empfehlungen, die in ei- nem früheren Konsensuspapier zur Differenzialdiagnose der MS [42] gegeben wurden, sind auch für die MOG-EM von Bedeutung.

Die hier vorgeschlagenen Kriterien können sicherlich dazu beitragen, pädiatrische Patienten mit einem hohen Risiko für eine MOG-IgG-assoziierte Erkrankung zu identifizieren, sie sind jedoch hauptsächlich für Erwachsene und Jugendliche konzipiert. Für die Testung auf MOG-IgG bei Kindern müssen keine so strengen Kriterien angelegt werden wie bei Erwachsenen, da MOGIgG bei Kindern mit erworbener demyelinisierender Erkrankung viel häufiger (bis zu $70 \%$, je nach Alter) vorliegt als bei Erwachsenen $(<1 \%$ in westlichen Ländern; wahrscheinlich $<5 \%$ in Japan und anderen asiatischen Ländern wegen niedrigerer MS-Prävalenz). Folglich ist das Risiko eines ungünstigen Verhältnisses von FP- zu RP-Ergebnissen bei Kindern geringer. Während die ADEM die vorherrschende klinische Assoziation bei kleinen Kindern ist, gibt es bei älteren Kindern mit MOG-Antikörpern eine Verschiebung in Richtung Präsentation mit $\mathrm{ON}$, Myelitis und/oder Hirnstammsymptomen [57].

\section{Schlussfolgerung und Ausblick}

In der vorliegenden Arbeit geben wir Empfehlungen zu möglichen Indikationen für die Testung von Patienten mit demyelinisierenden Erkrankungen des ZNS auf MOG-IgG und schlagen vorläufige Konsensuskriterien für die Diagnose der MOG-EM vor. Diagnostische und serologische Empfehlungen, wie die hier vorgelegten, sind angesichts der großen und stetig wachsenden Anzahl von Patienten, die gegenwärtig auf MOG-IgG getestet werden, und der damit verbundenen Risiken dringend erforderlich. Die Autoren sind sich jedoch bewusst, dass ihre Empfehlungen immer nur den aktuellen Wissensstand in einem sich entwickelnden Bereich widerspiegeln können und möglicherweise in der Zukunft angepasst werden müssen, wenn neue klinische und paraklinische Daten vorliegen und neuartige und optimierte Tests verfügbar werden. 


\begin{tabular}{|c|c|}
\hline \multicolumn{2}{|c|}{ Abkürzungen } \\
\hline$A D E M$ & $\begin{array}{l}\text { Akute disseminierte Enzephalo- } \\
\text { myelitis }\end{array}$ \\
\hline$A D E M-O N$ & ADEM mit wiederkehrender ON \\
\hline$A Q P 4$ & Aquaporin-4 \\
\hline CRION & $\begin{array}{l}\text { Chronische rezidivierende inflam- } \\
\text { matorische Optikusneuropathie }\end{array}$ \\
\hline CSF & Liquor cerebrospinalis \\
\hline$E M$ & Enzephalomyelitis \\
\hline Gd & Gadolinium \\
\hline IA & Immunadsorption \\
\hline $\lg A$ & Immunglobulin A \\
\hline $\lg G$ & Immunglobulin G \\
\hline $\lg M$ & Immunglobulin M \\
\hline IVMP & Intravenöses Methylprednisolon \\
\hline LETM & $\begin{array}{l}\text { Longitudinal extensive transverse } \\
\text { Myelitis }\end{array}$ \\
\hline MOG & $\begin{array}{l}\text { Myelin-Oligodendrozyten- } \\
\text { Glykoprotein }\end{array}$ \\
\hline MRT & Magnetresonanztomographie \\
\hline $\begin{array}{l}\text { MRZ- } \\
\text { Reaktion }\end{array}$ & $\begin{array}{l}\text { Masern-, Röteln- und Zoster-Virus- } \\
\text { Reaktion }\end{array}$ \\
\hline MS & Multiple Sklerose \\
\hline NMO & Neuromyelitis optica \\
\hline NMOSD & $\begin{array}{l}\text { NMO-Spektrum-Erkrankung (eng. } \\
\text { „NMO spectrum disorder") }\end{array}$ \\
\hline$O K B$ & Oligoklonale lgG-Banden \\
\hline ON & Optikusneuritis \\
\hline PEX & Plasmaaustausch \\
\hline$P M L$ & $\begin{array}{l}\text { Progressive multifokale Leuko- } \\
\text { enzephalopathie }\end{array}$ \\
\hline PPMS & Primär progrediente MS \\
\hline PRES & $\begin{array}{l}\text { Posteriores reversibles Enzephalo- } \\
\text { pathie-Syndrom }\end{array}$ \\
\hline RRMS & Schubförmig remittierende MS \\
\hline SPMS & Sekundär progrediente MS \\
\hline VEP & Visuell evozierte Potentiale \\
\hline WKS & Wirbelkörpersegmente \\
\hline ZNS & Zentralnervensystem \\
\hline
\end{tabular}

\section{Korrespondenzadresse}

\section{S. Jarius}

AG Molekulare Neuroimmunologie, Neurologische Klinik, Universitätsklinikum Heidelberg, Otto-Meyerhof-Zentrum Im Neuenheimer Feld 350, 69120 Heidelberg, Deutschland sven.jarius@med.uni-heidelberg.de

\section{B. Wildemann}

AG Molekulare Neuroimmunologie, Neurologische Klinik, Universitätsklinikum Heidelberg Im Neuenheimer Feld 400, 69120 Heidelberg, Deutschland brigitte.wildemann@med.uni-heidelberg.de

Danksagung. B. Wildemann dankt der Dietmar Hopp Stiftung und Merck Serono für die Förderung der Erforschung der MOG-lgG-assoziierten Enzephalomyelitis. A. Saiz wird von La Marató de TV3 (20141830) unterstützt. Die Autoren danken dem Myelitis e. V. für die Förderung der Übersetzung des englischen Originalartikels. Wir danken ferner der Guthy Jackson Charitable Foundation, der Deutschen Forschungsgemeinschaft, dem Ministeriums für Wissenschaft, Forschung und Kunst Baden-Württemberg, der Ruprecht-Karls-Universität Heidelberg und für finanzielle Unterstützung im Rahmen der jeweiligen Förderprogramme zum Open Access Publishing

Finanzierung. Die Arbeit von B. Wildemann wurde unterstützt von der Dietmar-Hopp-Stiftung, von Merck Serono und vom Bundesministerium für Bildung und Forschung (Kompetenznetzwerk Multiple Sklerose) sowie im Rahmen von OpenAccess-Publishing-Förderprogrammen durch die Deutsche Forschungsgemeinschaft, das Ministerium für Wissenschaft, Forschung und Kunst BadenWürttemberg, die Ruprecht-Karls-Universität Heidelberg und die Guthy Jackson Charitable Foundation. Die Übersetzung der vorliegenden Arbeit aus dem Englischen wurde gefördert durch Mittel aus de Selbsthilfeförderung folgender KrankenkassenSpitzenverbände an den Myelitis e. V., Deutschland: Verband der Ersatzkassen e. V. (VdEK), AOK-Bundesverband, BKK-Dachverband, IKK e. V., Knappschaft, Sozialversicherung für Landwirtschaft, Forsten und Gartenbau. Keine dieser Institutionen hatte Einfluss auf die Konzeption oder den Entwurf der Studie, auf die Datensammlung, -analyse oder -interpretation oder auf andere Aspekte, die für den vorliegenden Artikel relevant sind. Keiner der Autoren wurde von einem Pharmaunternehmen oder einer anderen Agentur dafür bezahlt, diesen Artikel zu schreiben. Die endgültige Verantwortung für die Entscheidung zur Veröffentlichung liegt bei den Autoren.

Verfügbarkeit von Daten und Materialien. Die Datensätze, die während der aktuellen Studie erstellt und/oder analysiert wurden, sind nicht öffentlich verfügbar, sind aber auf Anfrage bei dem entsprechenden Autor verfügbar.

Autorenbeteiligung. S. Jarius und B. Wildemann konzipierten das Projekt. S. Jarius sammelte und analysierte die Daten und schrieb den ersten Entwurf. Alle Autoren waren an der kritischen Überarbeitung des Manuskripts bezüglich wichtiger intellektueller Inhalte beteiligt.

\section{Einhaltung ethischer Richtlinien}

Interessenkonflikt. S. Jarius, N. Asgari, R.C. Dale und J. de Seze geben an, dass kein Interessenkonflikt besteht. 0 . Aktas erhielt Forschungsunterstützung durch die Deutsche Forschungsgemeinschaft (DFG), das Bundesministerium für Bildung und Forschung (BMBF; KKNMS; für NEMOS NationNMO FKZ 01GI1602) sowie Vortragshonorare und Reisestipendien von Bayer, Biogen, Genzyme, Medlmmune, Merck, Novartis, Roche, Sanofi und Teva. D. Franciotta erhielt ein Honorar für eine Präsentation von Biogen, die nicht mit der vorliegenden Arbeit in Zusammenhang steht. K. Fujihara ist in Beratungsgremien von Bayer Schering Pharma, Biogen Idec, Mitsubishi Tanabe Pharma Corporation, Novartis Pharma, Chugai Pharmaceutical, Ono Pharmaceutical, Nihon Pharmaceutical, Alexion Pharmaceuticals und Medlmmune tätig; hat von Bayer Schering Pharma, Biogen Idec, Eisai Inc., Mitsubishi Tanabe Pharma Corporation, Novartis Pharma, Astellas Pharma Inc., Takeda Pharmaceutical Company Limited, Asahi Kasei Medical Co., Daiichi Sankyo und Nihon Pharmaceutical Reisekosten und Honorare erhalten; ist in der Redaktion der Zeitschrift Clinical and Experimental Neuroimmunology; ist Beiratsmitglied des Sri Lanka Journal of Neurology und erhielt Forschungsunterstützung von Bayer Schering Pharma, Biogen Idec Japan, Asahi Kasei Medical, The ChemoSero-Therapeutic Research Institute, Teva Pharmaceutical, Mitsubishi Tanabe Pharma, Teijin Pharma, Chugai Pharmaceutical, Ono Pharmaceutical, Nihon Pharmaceutical, Genzyme Japan, Ministry of Education, Science and Technology of Japan und Ministry of Health, Welfare and Labor of Japan. A. Jacob wird von der NHS National Specialised Commissioning Group für NMO unterstützt und war Berater für Shire, Alexion, Terumo BCT und Chugai Pharmaceuticals und erhielt Forschungsgelder von Biogen und Alexion Pharmaceuticals. H.J. Kim hat Honorare für Vorträge und Beratungstätigkeiten erhalten von Bayer Schering Pharma, Biogen, Genzyme, HanAll BioPharma, Medlmmune, Merck Serono, Novartis, Teva-Handok und UCB; erhielt Forschungsunterstützung durch das Ministry of Science, ICT \& Future Planning und akzeptierte Forschungsfinanzierung von Genzyme, Kael-GemVax, Merck Serono, Teva-Handok und UCB; dient einem Lenkungsausschuss für Medlmmune; ist Mitherausgeber für die Zeitschrift Multiple Sclerosis Journal - Experimental, Translational and Clinical und ein assoziierter Herausgeber für das Journal of Clinical Neurology. I. Kleiter erhielt Honorare für Vorträge oder Beratertätigkeit von Bayer Schering Pharma, Biogen, Celltrion, Eisai, HanAll BioPharma, Medlmmune, Merck Serono, Novartis, Sanofi Genzyme, Teva-Handok und UCB sowie Forschungsunterstützung von Ministry of Science \& ICT, Sanofi Genzyme, Teva-Handok und UCB. Er ist ferner Mitglied eines Steering Committees von Medlmmune und Co-Editor/assoziierter Editor der folgenden Zeitschriften: Multiple Sclerosis Journal - Experimental, Translational and Clinical; Journal of Clinical Neurology. T. Kümpfel hat Reisekosten und persönliche Entschädigungen von Bayer Healthcare, Teva Pharma, Merck Serono, Novartis, Sanofi Genzyme und Biogen Idec sowie Zuschüsse von Chugai Pharma und Novartis erhalten. M. Levy erhält Unterstützung von Quest Diagnostics. J. Palace wird teilfinanziert durch einen spezialisierten nationalen Service für Neuromyelitis optica und angeborene Myasthenie. Sie erhielt Unterstützung für wissenschaftliche Tagungen und Honorare für Beratungsleistungen von Merck Serono, Biogen Idec, Novartis, Teva, Chugai Pharma, Bayer Schering, Alexion, Roche, Genzyme, Medlmmune, Euroimmun, MedDay, Abide und ARGENX sowie 
Forschungsunterstützung von MerckSerono, Novartis, Biogen Idec, Teva, Abide und Bayer Schering. Ihr Hospital Trust hat Forschungsunterstützung erhalten im Rahmen ihrer klinischen Tätigkeit für den RSS. Sie hat ferner Grants erhalten von der MS Society, der GuthyJackson Charitable Foundation, dem NIHR, dem Oxford Health Services Research Committee, EDEN, MRC und John Fell für wissenschaftliche Studien. F. Paul erhielt Honorare und Forschungsunterstützung von Alexion, Bayer, Biogen, Chugai, Merck Serono, Novartis, Genzyme, Medlmmune, Shire, Teva und ist in wissenschaftlichen Beiräten für Alexion, Medlmmune und Novartis tätig. Er erhielt finanzielle Unterstützung von der Deutschen Forschungsgemeinschaft (DFG Exc 257), dem Bundesministerium für Bildung und Forschung (Kompetenznetzwerk Multiple Sklerose), der Guthy-Jackson Charitable Foundation, dem EU-Rahmenprogramm 7, und der National Multiple Sclerosis Society der USA. K. Ruprecht erhielt Forschungsunterstützung vom Bundesministerium für Bildung und Forschung (BMBF/KKNMS, Kompetenznetzwerk Multiple Sklerose) und Novartis sowie Reisekosten bzw. Vortragsgebühren von der Guthy-Jackson Charitable Foundation, Bayer Healthcare, Biogen Idec, Merck Serono, Sanofi-Aventis, Genzyme, Teva Pharmaceuticals und Novartis. A. Saiz wird von La Marató de TV3 (20141830) unterstützt. C. Trebst hat Honorare für Beratung und Gutachten von der Bayer Vital $\mathrm{GmbH}$, der Biogen Idec GmbH, der Genzyme GmbH und Novartis Pharmaceuticals erhalten, die nicht mit der vorliegenden Arbeit in Zusammenhang stehen. B.G. Weinshenker erhält Lizenzgebühren von RSR Ltd, Universität Oxford, Hospices Civil de Lyon, und MVZ Labor PD Dr. Volkmann und Kollegen GbR für ein Patent zu NMO-IgG als diagnostischen Test für NMO und verwandte Erkrankungen. Er erhält eine persönliche Entschädigung für die Mitgliedschaft in einem Ausschuss für klinische Studien bei NMO, der von den Pharmaunternehmen Medlmmune und Alexion durchgeführt wird. Er ist Berater für Caladrius Biosciences bezüglich möglicher klinischer Studien bei NMO. Er ist Berater für Caladrius Biosciences, Brainstorm Therapeutics, Roivant Sciences und Chugai Pharma hinsichtlich möglicher klinischer Studien bei NMO. Er erhält eine persönliche Entschädigung für die Teilnahme an einem Data Safety Monitoring Board für Novartis für klinische Studien. Die Arbeit von B. Wildemann wurde durch Forschungsbeihilfen der Dietmar-Hopp-Stiftung, von Merck Serono und des Bundesministeriums für Bildung und Forschung (Kompetenznetzwerk Multiple Sklerose) unterstützt.

Dieser Beitrag beinhaltet keine von den Autoren durchgeführten Studien an Menschen oder Tieren.

Open Access. Dieser Artikel wird unter der Creative Commons Namensnennung 4.0 International Lizenz (http://creativecommons.org/licenses/by/4.0/deed. de) veröffentlicht, welche die Nutzung, Vervielfältigung, Bearbeitung, Verbreitung und Wiedergabe in jeglichem Medium und Format erlaubt, sofern Sie den/die ursprünglichen Autor(en) und die Quelle ordnungsgemäß nennen, einen Linkzur Creative Commons Lizenz beifügen und angeben, ob Änderungen vorgenommen wurden.

\section{Literatur}

1. Akaishi T, Nakashima I, Takeshita T et al (2016) Lesion length of optic neuritis impacts visual prognosis in neuromyelitis optica. J Neuroimmunol 293:28-33
2. Andersson M, Alvarez-Cermeno J, Bernardi G et al (1994) Cerebrospinal fluid in the diagnosis of multiple sclerosis: a consensus report. J Neurol Neurosurg Psychiatr 57:897-902

3. Arnold DM, Crowther MA, Meyer RM et al (2010) Misleading hepatitis B test results due to intravenous immunoglobulin administration: implications for a clinical trial of rituximab in immune thrombocytopenia. Transfusion 50:2577-2581

4. Baumann M, Grams A, Djurdjevic T et al (2018) MRI of the first event in pediatric acquired demyelinating syndromes with antibodies to myelin oligodendrocyte glycoprotein. J Neurol 265:845-855

5. Bouzar M, Daoudi S, Hattab S et al (2017) Neuromyelitis optica spectrum disorders with antibodies to myelin oligodendrocyte glycoprotein or aquaporin-4: clinical and paraclinical characteristics in Algerian patients. J Neurol Sci 381:240-244

6. Chalmoukou K, Alexopoulos H, Akrivou S et al (2015) Anti-MOG antibodies are frequently associated with steroid-sensitive recurrent optic neuritis. Neurol Neuroimmunol Neuroinflamm 2:e131

7. Cobo-Calvo Á, Ruiz A, Poulat A-Let al (2016) MOGantibody-related disorders cohort description: common features and uncommon presentations. Mult Scler 22:405

8. Cortese A, Franciotta D, Alfonsi E et al (2016) Combined central and peripheral demyelination: clinical features, diagnostic findings, and treatment. J Neurol Sci 363:182-187

9. Di Pauli F, Mader S, Rostasy K et al (2011) Temporal dynamics of anti-MOG antibodies in CNS demyelinating diseases. Clin Immunol 138:247-254

10. FanS, Xu Y, Ren Hetal (2018) Comparison of myelin oligodendrocyte glycoprotein (MOG)-antibody disease and AQP4-IgG-positive neuromyelitis optica spectrum disorder (NMOSD) when they co-exist with anti-NMDA (N-methyl-D-aspartate) receptor encephalitis. Mult Scler Relat Disord 20:144-152

11. Frau J, Villar LM, Sardu C et al (2018) Intrathecal oligoclonal bands synthesis in multiple sclerosis: is it always a prognostic factor? J Neurol 265:424-430

12. Garcia L, Huh YO, Fischer HE et al (1987) Positive immunohematologic and serologic test results due to high-dose intravenous immune globulin administration. Transfusion 27:503

13. Hacohen $Y$, Wong YY, Lechner $C$ et al (2018) Disease course and treatment responses in children with relapsing myelin oligodendrocyte glycoprotein antibody-associated disease. JAMA Neurol 75(4):478-487

14. Hoftberger R, Sepulveda $M$, Armangue $T$ et al (2015) Antibodies to MOG and AQP4 in adults with neuromyelitis optica and suspected limited forms of the disease. Mult Scler 21:866-874

15. Hohlfeld R, Dornmair K, Meinl E et al (2016) The search for the target antigens of multiple sclerosis, part 2: CD8+ T cells, B cells, and antibodies in the focus of reverse-translational research. Lancet Neurol 15:317-331

16. Jarius $S$, Aboul-Enein F, Waters $P$ et al (2008) Antibody to aquaporin-4 in the long-term course of neuromyelitis optica. Brain 131:3072-3080

17. Jarius S, Eichhorn P, Albert MH et al (2007) Intravenous immunoglobulins contain naturally occurring antibodies that mimic antineutrophil cytoplasmic antibodies and activate neutrophils in a TNFalpha-dependent and Fc-receptorindependent way. Blood 109:4376-4382
18. Jarius $S$, Eichhorn $P$, Franciotta $D$ et al (2017) The MRZ reaction as a highly specific marker of multiple sclerosis: re-evaluation and structured review of the literature. J Neurol 264:453-466

19. Jarius $S$, Franciotta D, Bergamaschi R et al (2010) $\operatorname{lgM}$ antibodies to aquaporin-4 in neuromyelitis optica and related disorders. Clin Chem Lab Med 48(5):659-663

20. Jarius S, Kleiter I, Ruprecht $K$ et al (2016) MOGIgG in NMO and related disorders: a multicenter study of 50 patients. Part 3: brainstem involvement - frequency, presentation and outcome. JNeuroinflammation 13:281

21. Jarius S, Metz I, Konig FB et al (2016) Screening for MOG-IgG and 27 other anti-glial and anti-neuronal autoantibodies in 'pattern II multiple sclerosis' and brain biopsy findings in a MOG-lgG-positive case. Mult Scler 22:1541-1549

22. Jarius S, Paul F, Franciotta D et al (2011) Cerebrospinal fluid findings in aquaporin-4 antibody positive neuromyelitis optica: results from 211 lumbar punctures. J Neurol Sci 306:82-90

23. Jarius S, Ruprecht K, Kleiter I et al (2016) MOG$\mathrm{lgG}$ in NMO and related disorders: a multicenter study of 50 patients. Part 2: epidemiology, clinical presentation, radiological and laboratory features, treatment responses, and long-term outcome. JNeuroinflammation 13:280

24. Jarius S, Ruprecht K, Kleiter I et al (2016) MOG$\mathrm{IgG}$ in NMO and related disorders: a multicenter study of 50 patients. Part 1: frequency, syndrome specificity, influence of disease activity, long-term course, association with AQP4-IgG, and origin. JNeuroinflammation 13:279

25. Jarius S, Ruprecht K, Stellmann JP et al (2018) MOG-IgG in primary and secondary chronic progressive multiple sclerosis: a multicenter study of 200 patients and review of the literature. J Neuroinflammation 15:88. https://doi.org/10. 1186/s12974-018-1108-6

26. Jarius S, Ruprecht K, Wildemann B et al (2012) Contrasting disease patterns in seropositive and seronegative neuromyelitis optica: a multicentre study of 175 patients. J Neuroinflammation 9:14

27. Jarius S, Wildemann B (2013) Aquaporin-4 antibodies (NMO-lgG) as a serological marker of neuromyelitis optica: a critical review of the literature. Brain Pathol 23:661-683

28. Jurynczyk M, Geraldes R, Probert F et al (2017) Distinct brain imaging characteristics of autoantibody-mediated CNS conditions and multiple sclerosis. Brain 140:617-627

29. Jurynczyk M, Messina S, Woodhall MR et al (2017) Clinical presentation and prognosis in MOGantibody disease: a UK study. Brain 140:3128-3138

30. Jurynczyk M, Tackley G, Kong $Y$ et al (2017) Brain lesion distribution criteria distinguish MS from AQP4-antibody NMOSD and MOG-antibody disease. J Neurol Neurosurg Psychiatr 88:132-136

31. Kim SM, Woodhall MR, Kim JS et al (2015) Antibodies to MOG in adults with inflammatory demyelinating disease of the CNS. Neurol Neuroimmunol Neuroinflamm 2:e163

32. Kister I, Paul F (2015) Pushing the boundaries of neuromyelitis optica: does antibody make the disease? Neurology 85:118-119

33. Kitley J, Waters P, Woodhall M et al (2014) Neuromyelitis optica spectrum disorders with aquaporin-4 and myelin-oligodendrocyte glycoprotein antibodies: a comparative study. JAMA Neurol 71:276-283

34. Kitley J, Woodhall M, Waters P et al (2012) Myelinoligodendrocyte glycoprotein antibodies in adults 
with a neuromyelitis optica phenotype. Neurology 79:1273-1277

35. Konig FB, Wildemann B, Nessler S et al (2008) Persistence of immunopathological and radiological traits in multiple sclerosis. Arch Neurol 65:1527-1532

36. Mader S, Gredler V, Schanda K et al (2011) Complement activating antibodies to myelin oligodendrocyte glycoprotein in neuromyelitis optica and related disorders. J Neuroinflammation 8:184

37. Mariotto S, Ferrari S, Monaco S et al (2017) Clinical spectrum and lgG subclass analysis of antimyelin oligodendrocyte glycoprotein antibodyassociated syndromes: a multicenter study. JNeurol 264:2420-2430

38. Matsuda R, Kezuka T, Umazume A et al (2015) Clinical profile of anti-myelin oligodendrocyte glycoprotein antibody seropositive cases of optic neuritis. Neuroophthalmology 39:213-219

39. Matthews L, Marasco R, Jenkinson M et al (2013) Distinction of seropositive NMO spectrum disorder and MS brain lesion distribution. Neurology 80:1330-1337

40. Mayer MC, Breithaupt C, Reindl M et al (2013) Distinction and temporal stability of conformational epitopes on myelin oligodendrocyte glycoprotein recognized by patients with different inflammatory central nervous system diseases. J Immunol 191:3594-3604

41. Mealy MA, Whetstone A, Orman G et al (2015) Longitudinally extensive optic neuritis as an MRI biomarker distinguishes neuromyelitis optica from multiple sclerosis. J Neurol Sci 355:59-63

42. Miller DH, Weinshenker BG, Filippi M et al (2008) Differential diagnosis of suspected multiple sclerosis: a consensus approach. Mult Scler 14:1157-1174

43. Miyazaki T, Nakajima $H$, Motomura M et al (2016) A case of recurrent optic neuritis associated with cerebral and spinal cord lesions and autoantibodies against myelin oligodendrocyte glycoprotein relapsed after fingolimod therapy. RinshoShinkeigaku 56:265-269

44. Montcuquet A, Collongues N, Papeix C et al (2016) Effectiveness of mycophenolate mofetilas first-line therapy in AQP4-IgG, MOG-lgG, and seronegative neuromyelitis optica spectrum disorders. Mult Scler 23(10):1377-1384

45. Nishikawa Y, Oku H, Tonari K et al (2016) A case of CRION with high titer of MOG antibody. NeuroOphthalmol Japan 33:27-31

46. Oshiro A, NakamuraS, TamashiroKetal (2016) AntiMOG + neuromyelitis optica spectrum disorders treated with plasmapheresis. No To Hattatsu 48:199-203

47. Pache $F$, Zimmermann $\mathrm{H}$, Mikolajczak J et al (2016) MOG-IgG in NMO and related disorders: a multicenter study of 50 patients. Part 4: afferent visual system damage after optic neuritis in MOGlgG-seropositive versus AQP4-lgG-seropositive patients. J Neuroinflammation 13:282

48. Peschl P, Schanda K, Zeka B et al (2017) Human antibodies against the myelin oligodendrocyte glycoprotein can cause complement-dependent demyelination. J Neuroinflammation 14:208

49. Petzold A, Plant GT (2014) Chronic relapsing inflammatory optic neuropathy: a systematic review of 122 cases reported. J Neurol 261:17-26

50. Probstel AK, Dornmair K, Bittner R et al (2011) Antibodies to MOG are transient in childhood acute disseminated encephalomyelitis. Neurology 77:580-588
51. Ramanathan S, Dale RC, Brilot F (2016) AntiMOG antibody: the history, clinical phenotype, and pathogenicity of a serum biomarker for demyelination. Autoimmun Rev 15:307-324

52. Ramanathan S, Prelog K, Barnes EH et al (2016) Radiological differentiation of optic neuritis with myelin oligodendrocyte glycoprotein antibodies, aquaporin-4 antibodies, and multiple sclerosis. Mult Scler 22:470-482

53. Ramanathan S, Reddel SW, Henderson A et al (2014) Antibodies to myelin oligodendrocyte glycoprotein in bilateral and recurrent optic neuritis. Neurol Neuroimmunol Neuroinflamm 1:e40

54. Reiber H (1998) Cerebrospinal fluid - physiology analysis and interpretation of protein patterns for diagnosis of neurological diseases. Mult Scler 4:99-107

55. Reiber H, Teut M, Pohl D et al (2009) Paediatric and adult multiple sclerosis: age-related differences and time course of the neuroimmunological response in cerebrospinal fluid. Mult Scler 15:1466-1480

56. Reiber H, Ungefehr S, Jacobi C (1998) The intrathecal, polyspecific and oligoclonal immune response in multiple sclerosis. Mult Scler 4:111-117

57. Reindl M, Jarius S, Rostasy K et al (2017) Myelin oligodendrocyte glycoprotein antibodies: how clinically useful are they? Curr Opin Neurol 30(3):295-301

58. Sato DK, Callegaro D, Lana-Peixoto MA et al (2014) Distinction between MOG antibody-positive and AQP4 antibody-positive NMO spectrum disorders. Neurology 82:474-481

59. Sepulveda M, Armangue T, Martinez-Hernandez E et al (2016) Clinical spectrum associated with MOG autoimmunity in adults: significance of sharing rodent MOG epitopes. J Neurol 263:1349-1360

60. Spadaro M, Gerdes LA, Krumbholz M et al (2016) Autoantibodies to MOG in a distinct subgroup of adult multiple sclerosis. Neurol Neuroimmunol Neuroinflamm 3:e257

61. Spadaro M, Gerdes LA, Mayer MC et al (2015) Histopathology and clinical course of MOGantibody-associated encephalomyelitis. Ann Clin Transl Neurol 2:295-301

62. Storoni M, Davagnanam I, Radon M et al (2013) Distinguishing optic neuritis in neuromyelitis optica spectrum disease from multiple sclerosis: a novel magnetic resonance imaging scoring system. J Neuroophthalmol 33:123-127

63. Titulaer MJ, Hoftberger R, lizuka T et al (2014) Overlapping demyelinating syndromes and anti$\mathrm{N}$-methyl-D-aspartate receptor encephalitis. Ann Neurol 75:411-428

64. Tsuburaya RS, Miki N, Tanaka K et al (2015) Anti-myelin oligodendrocyte glycoprotein (MOG) antibodies in a Japanese boy with recurrent optic neuritis. Brain Dev 37:145-148

65. Van Pelt ED, Wong YY, Ketelslegers IA et al (2015) Neuromyelitis optica spectrum disorders: comparison of clinical and magnetic resonance imaging characteristics of AQP4-IgG versus MOGIgG seropositive cases in the Netherlands. Eur J Neurol 23(3):580-587

66. Waters P, Woodhall M, O'connor KC et al (2015) MOG cell-based assay detects non-MS patients with inflammatory neurologic disease. Neurol Neuroimmunol Neuroinflamm 2:e89

67. Wildemann B, Jarius S, Schwarz A etal (2017)Failure of alemtuzumab therapy to control mog-igg encephalomyelitis. Neurology 89:207-209. https://doi. org/10.1212/WNL.0000000000004087
68. Wingerchuk DM, Banwell B, Bennett JL et al (2015) International consensus diagnostic criteria for neuromyelitis optica spectrum disorders. Neurology 85:177-189

69. Wingerchuk DM, Lennon VA, Pittock SJ et al (2006) Revised diagnostic criteria for neuromyelitis optica. Neurology 66:1485-1489

70. Zamvil SS, Slavin AJ (2015) Does MOG Ig-positive AQP4-seronegative opticospinal inflammatory disease justify a diagnosis of NMO spectrum disorder? Neurol Neuroimmunol Neuroinflamm 2:e62

71. Zhou L, Huang Y, Li H et al (2017) MOG-antibody associated demyelinating disease of the CNS: a clinical and pathological study in Chinese Han patients. J Neuroimmunol 305:19-28 